\title{
Management of (Peri)Pancreatic Collections in Acute Pancreatitis
}

\author{
Mihailo Bezmarevića, b Sven M. van Dijk ${ }^{b, c}$ Rogier P. Voermans ${ }^{d}$ \\ Hjalmar C. van Santvoort ${ }^{\mathrm{e}}$ f Marc G. Besselink ${ }^{\mathrm{b}}$ Dutch Pancreatitis Study Group \\ ${ }^{a}$ Department of Hepatobiliary and Pancreatic Surgery, Clinic for General Surgery, Military Medical Academy, \\ University of Defense, Belgrade, Serbia; ${ }^{b}$ Department of Surgery, Amsterdam Gastroenterology and Metabolism, \\ Amsterdam UMC, University of Amsterdam, Amsterdam, The Netherlands; ${ }^{\mathrm{C}}$ Department of Research and \\ Development, St. Antonius Hospital, Nieuwegein, The Netherlands; ${ }^{\mathrm{d} D e p a r t m e n t}$ of Gastroenterology and \\ Hepatology, Amsterdam Gastroenterology and Metabolism, Amsterdam UMC, University of Amsterdam, \\ Amsterdam, The Netherlands; ${ }^{e}$ Department of Surgery, St. Antonius Hospital, Utrecht, \\ The Netherlands; ${ }^{\text {}}$ Department of Surgery, University Medical Center Utrecht, Utrecht, The Netherlands
}

Keywords

Acute pancreatitis · Fluid collection - Management .

Surgery $\cdot$ Minimally invasive procedure

\section{Abstract}

The development of (peri)pancreatic fluid collections are frequent local complications in acute pancreatitis. These collections are classified as early (acute peripancreatic fluid collection or acute necrotic collection) or late (walled-off necrosis or pseudocyst). The majority of pancreatic fluid collections resolve spontaneously and do not require intervention. However, infection may require intervention. Interventions may include endoscopic or percutaneous catheter drainage, or in a next step endoscopic or surgical necrosectomy, minimally invasive or open. The best timing for the first intervention is still under investigation. Whereas some use antibiotics to postpone intervention until the stage of walled-off necrosis, others drain earlier. Endoscopic drainage of (peri)pancreatic fluid collections is now the preferred approach of drainage due to reduced morbidity as compared to surgical or percutaneous drainage. However, each collection must be treated according to a tailored approach. The final treatment should take into consideration anatomic characteristics, patient preference, comorbidity profile of the patient, and physician discretion. This review summarizes the current evidence on the treatment of (peri)pancreatic fluid collections.

(c) 2019 The Author(s)

Published by S. Karger AG, Basel

\section{Introduction}

Acute pancreatitis (AP) accounts for over 50\% of all hospital admissions for pancreatic disease and still represents one of the most unpredictable diseases of the digestive system [1]. As such, AP can be associated with various local or systemic complications, and in its most severe form, it can lead to multiple organ failure and even death [1-4]. Moderate severe pancreatitis is defined as AP that is accompanied with local complications (e.g., necrosis) of the pancreatic and/or peripancreatic tissue and transient organ failure, and severe pancreatitis is defined as local complications in combination with persistent organ failure [2]. Approximately 15-20\% of patients develop moderate severe or severe form of the disease. In nearly one-third of this group, infection of the (peri)pancreatic necrosis occurs, which is associated with mortality rates varying from $15 \%$ to $39 \%$ [4-8]. Approximately half of AP deaths occur within the first 2 weeks of the disease, mostly due to multiple organ failure as a result of severe systemic inflammatory response. The remainder of deaths occur later from complications secondary to the infection of (peri)pancreatic necrosis and the subsequent interventions $[9,10]$.

Effective management requires accurate diagnosis and treatment by a multidisciplinary team of specialized surgeons, gastroenterologists, intensivists, and radiologists working in tandem to minimize morbidity and mortality

\section{KARGER \\ E-Mail karger@karger.com www.karger.com/vis} (c) 2019 The Author(s) Karger
Published by S. Karger AG, Basel Open access
This is an Open Access article licensed under the Creative Commons Attribution-NonCommercial-4.0 International License (CC BY-NC) (http://www.karger.com/Services/OpenAccessLicense), applicable to mercial purposes requires written permission.
Marc G. Besselink

Department of Surgery, Amsterdam Gastroenterology and Metabolism

Amsterdam UMC, University of Amsterdam

Meibergdreef 9, NL-1105 AZ Amsterdam (The Netherlands)

E-Mailm.g.besselink@amc.uva.nl 
rates. Over the last decades, treatment has evolved from aggressive open surgery to a more conservative approach with minimally invasive techniques. This review will provide and summarize the existing evidence on the treatment of (peri)pancreatic fluid collections and comment on the challenges that lie ahead.

\section{Definitions of Peripancreatic Fluid Collections}

One of the most frequent local complications in AP is the development of (peri)pancreatic fluid collections (PFC). According to the 2012 revised Atlanta classification [2], PFC can be classified based on acuity and content into four distinctive categories: acute peripancreatic fluid collection (APFC), acute necrotic collections (ANC), pancreatic pseudocysts (PP), and walled-off necrosis (WON). According to this classification, PP is defined as well-circumscribed, homogeneous fluid collection surrounded by a well-defined wall without associated necrotic tissue in this collection and is seen $>4$ weeks after onset of interstitial edematous pancreatitis. A PP will have a strictly liquid substance, and will therefore by definition never occur in necrotizing pancreatitis. Prior to 4 weeks after onset of AP, these fluid collections are termed APFC and have no wall $[2,11]$. APFC and PP may arise from the rupture of the main pancreatic duct or one of the smaller peripheral side branches of the pancreatic ductal system. It is not necessary that all APFC and PP have direct communication with a pancreatic duct, as they also may arise from local edema secondary to pancreatic inflammation [2, 12]. Usually, these collections will resolve spontaneously $[2,13,14]$.

ANC can occur as a result of necrotizing pancreatitis. These collections have both fluid and necrotic components. This can be seen as a more heterogeneous presentation on abdominal imaging (e.g., contrast-enhanced computed tomography or magnetic resonance imaging). The necrosis will develop in the first 3-5 days after onset of disease, and therefore an early scan may underestimate the amount of necrosis. It is therefore advised to perform imaging after 5 days after onset of disease. In the acute phase, it can be difficult to differentiate between a APFC and ANC. It may take 1-2 weeks after initial diagnosis of a fluid collection to make a clear distinction $[2,14]$. Necrotic pancreatitis may present as necrosis of the pancreatic parenchyma, usually accompanied with peripancreatic necrosis. In a small group of patients, there will be solely extrapancreatic necrosis (EXPN), without necrosis of the parenchyma. Around 2-6 weeks after onset of AP, the necrotic tissue begins to liquefy giving the appearance of both liquid and solid components in clearly demarcated area (WON) [15]. Hence, the term WON refers to a matured ANC that has well-demarcated and thickened wall between the necrotic and viable pancreatic tissue [2].

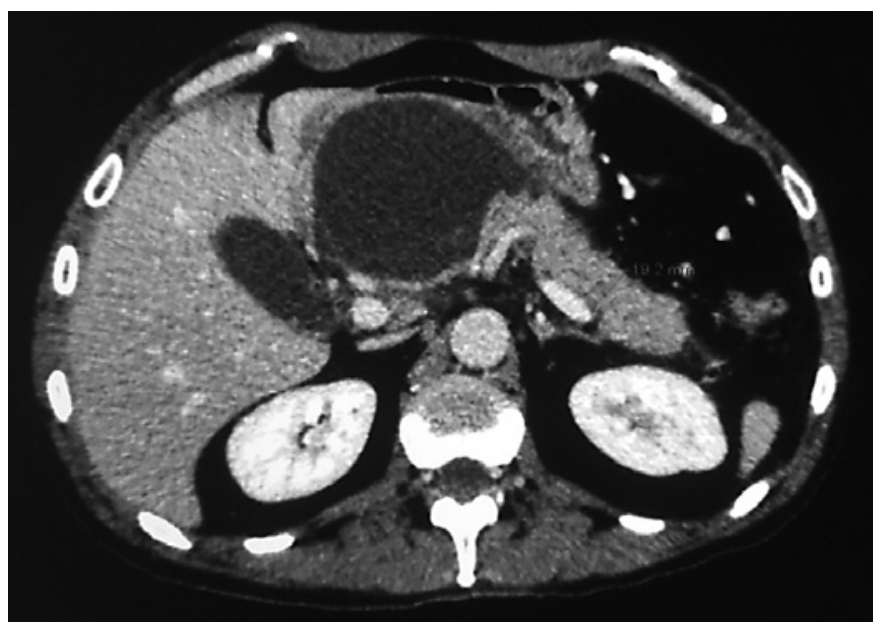

Fig. 1. CT scan of a pancreatic fluid collection in a 63-year-old male 56 days after onset of acute pancreatitis. Ultrasound or MRI is required to exclude the presence of pancreatic necrosis in this collection.

\section{Indication and Timing for Intervention of (Peri) Pancreatic Fluid and Necrotic Collections}

The indication for intervention of PFCs has evolved over the years. Previously [16], PFCs were considered for drainage based on the presence of symptoms and/or complications such as abdominal pain, gastrointestinal obstruction, vascular compression, biliary obstruction, or infection, as well as on the size of the collection. However, guidelines have evolved into the situation that drainage is only necessary in infected collections, or in the exceptional case of symptomatic fluid collections, after a long period of conservative treatment [17].

Generally, intervention in PFCs is deemed preferable if is performed after the collection is encapsulated or demarcated (generally after around 4 weeks). This facilitates entering into the collection with a lower probability of free perforation, and a higher likelihood of successful drainage due to greater adherence of collection to the gastrointestinal lumen for endoscopic approach, for example [18]. Furthermore, postponing the intervention decreased mortality due to reduced proinflammatory response in already critically ill patients, reduced postoperative complications, and is technically more easy to perform with a reduced number of adverse events $[19,20]$. However, these arguments have all been extrapolated from direct open surgical necrosectomy. It is unclear if the same applies for the current minimally invasive procedures.

PP is an encapsulated collection of fluid with a welldefined inflammatory wall usually outside the pancreas without necrosis. This entity usually requires $>4$ weeks after onset of interstitial edematous pancreatitis to mature [2]. PP on contrast-enhanced CT is presented as 
well-circumscribed, usually round or oval homogeneous fluid density without non-liquid component (Fig. 1) [2, $11,21]$. Spontaneous resolution of PPs ranges from 8 to $70 \%$ and depends on several factors: presence of multiple cysts, location in the pancreatic tail, communication with the main pancreatic duct and co-existence of stricture, and increasing size during follow-up [22-24]. Intervention should be delayed up to 6 weeks from onset of AP, in order to let the PP wall maturate $[3,12,24]$. This delay of intervention aids in the success of any type of drainage [25]. Exception of this delay is occurrence of life-threatening events such as erosion of the surrounding blood vessels with hemorrhage with or without cyst rupture; however, this is very uncommon. PPs less than $3 \mathrm{~cm}$ in diameter are usually asymptomatic and do not require intervention. There is no absolute size at which intervention is mandated; however, increased risk of complications has been reported of cyst $>5 \mathrm{~cm}$ in diameter, especially in the absence of decreasing cysts size over 6 weeks $[2,18,24,26]$. Uncomplicated and asymptomatic PPs, remaining stable or even diminishing in size, can be managed conservatively. PPs that are larger in size may become symptomatic and are a relative indication for intervention. Symptoms include persistent abdominal pain, flank or back pain, partial or complete gastric or duodenal outlet obstruction with early satiety, anorexia, weight loss, abdominal distension, vomiting or reflux, biliary obstruction, and jaundice. As mentioned, more severe complications include PP infection, bleeding into cyst, PP rupture, and gastroduodenal and/or splenic artery erosions [18, 27-29], where intervention is necessary.

During the first 2-4 weeks after occurrence of ANC, it will either resolve or become encapsulated (Fig. 2). Most of ANCs are sterile and will resolve with conservative management, but in cases with infection, further intervention will be required [17]. An asymptomatic WON does not require intervention regardless of its size, because it may resolve spontaneously over time $[8,30]$. Even in large collections, the majority will resolve spontaneously. However, it has been shown that larger size of WON, extension of WON to the paracolic gutter, and extension of necrosis are associated with the need for intervention [31-33]. Intervention in a sterile collection carries the risk of secondary iatrogenic infection, with all its associated morbidity and mortality. A symptomatic sterile necrotic collection (e.g., abdominal pain or mechanical obstruction) may require intervention; however, due to the risk of secondary iatrogenic infection, the focus should be on conservative management and interventions should be delayed for 6-8 weeks or longer [8]. In nearly $30 \%$ of patients, the (peri)pancreatic necrosis will become infected, requiring intervention in the vast majority of patients (Fig. 3). Only a small percentage of patients can be treated with antibiotics only $[34,35]$. Since

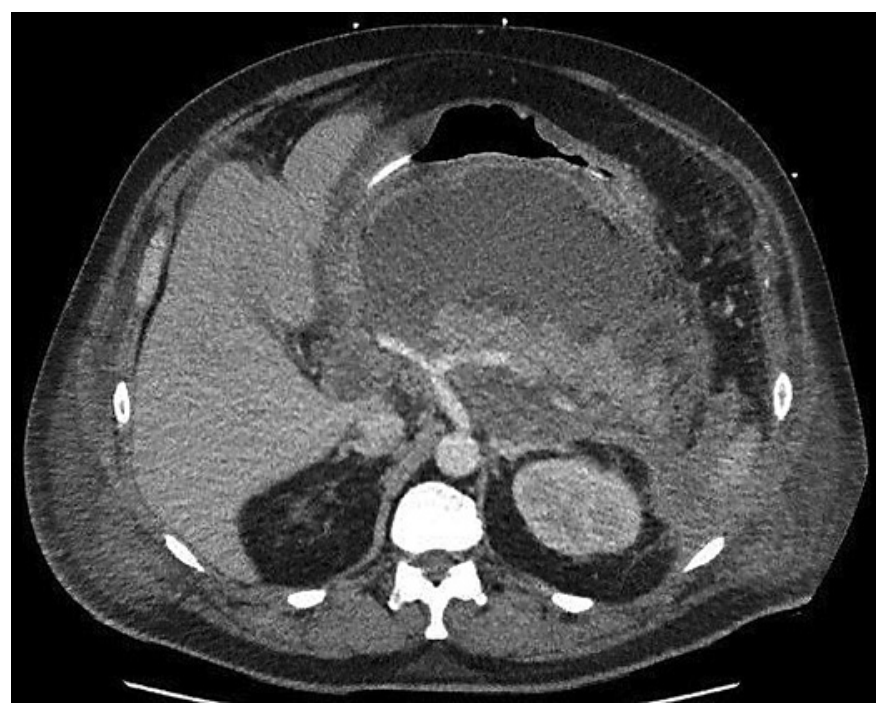

Fig. 2. Acute necrotic collection in a 57 -year-old male 17 days after onset of acute pancreatitis.

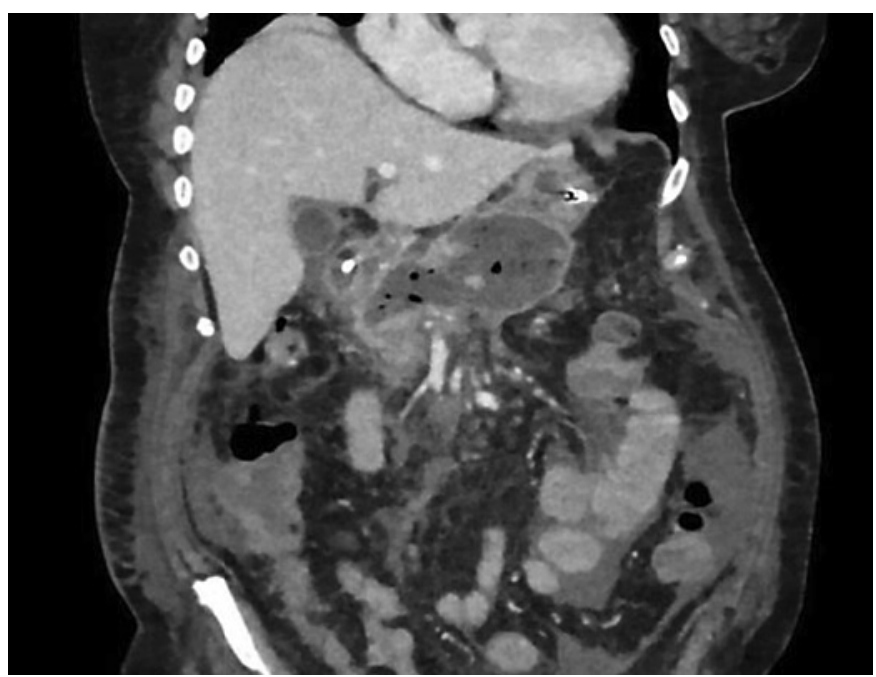

Fig. 3. Walled-off necrosis with infection as documented by the impact gas in a 74-year-old female 27 days after onset of acute pancreatitis.

early open surgery is associated with high morbidity and mortality, it should be avoided whenever possible. Mesenteric ischemia and abdominal compartment syndrome as a direct consequence of AP may represent only two absolute indications for early open surgical intervention [36]. Nerosectomy in the first 2 weeks carries a high risk of morbidity and mortality and therefore should be avoided $[19,20,36]$. Percutaneous drainage, however, can be performed early in the course of infected necrotizing pancreatitis. Currently, the Dutch Pancreatitis Study Group is performing the POINTER trial (http://www.isrctn. com/ISRCTN33682933), which randomizes 104 patients between the immediate catheter drainage after diagnosing infected necrosis versus current standard treatment 
with postponing catheter drainage under antibiotic treatment (preferably until walled-off necrosis). If necessary, a necrosectomy will be performed and postponed, if feasible, until the stage of walled-off necrosis in both treatment arms. This trial has currently recruited over $75 \%$ of patients and results are expected in 2020.

\section{Management of Acute Peripancreatic Fluid Collections and Pancreatic Pseudocysts}

As stated above, APFC do not require any intervention and can be treated conservatively. If there is an indication for intervention of a PP, there are several techniques available, including percutaneous, endoscopic, and surgical drainage. Endoscopic transmural drainage has essentially replaced surgical and percutaneous drainage.

In the last two decades, studies comparing the different treatment techniques show significant heterogeneity in the included studies and a clear conclusion cannot be made [37-45]. The adequate technique which should be used depends on anatomy, PP localization, size, content, and communication with the main pancreatic duct. In one of the largest studies comparing percutaneous and surgical drainage of PPs, Morton et al. [44] concluded that surgical approach has fewer complications, less inpatient mortality, and reduced hospital stay. Similar results were published by Heider et al. [45] who favored surgical over percutaneous approach. Only two studies published almost 3 decades ago favored percutaneous over surgical approach in terms of higher mortalities, morbidities [46], and re-interventions [47]. Regarding the success rate, it seems that surgical approach has had higher rate of clinical success, but the overall success rate has been equivalent across all techniques [40-45]. On the other hand, surgical drainage may still be preferred because it avoids the need of an external catheter and reduces the risk of developing external pancreatic fistula. When comparing endoscopic procedures with other techniques for PP treatment, endoscopic transmural approach has showed benefit in hospital stay reduction, treatment costs, and quality of life [37$39,41,46]$. Therefore, endoscopic approach is preferred when anatomy of the $\mathrm{PP}$ allows for direct drainage into the stomach or duodenum. Only if the cyst is located away from the stomach or duodenum, surgical or percutaneous approach should be considered. Also, percutaneous drainage can be helpful in cases of fragile patients with severe comorbidities who cannot tolerate any other procedure; however, due to the risk of pancreatocutaneous fistula, this is not the preferred treatment route. It is important to evaluate the communication between PPCs and main pancreatic duct due to decreased rate of clinical success of transmural drainage alone, in cases in which this communication is present. In such cases, combined endoscopic transmural and transpapillary drainage may have benefit over single approach modality [48]. However, another study could not find any benefit from combination of transpapillary and transmural over transmural drainage alone [49], and at the moment, the use of this combined approach remains ambiguous.

\section{Management of Acute Necrotic Collections and Walled-Off Necrosis}

Invasive interventional procedures for acute necrotizing pancreatitis include radiological, endoscopic, and surgical approach. Previously, a primary open necrosectomy was the preferred treatment of choice. This was associated with high rates of mortality and morbidity. Currently, the treatment of choice is the step-up approach, in which the necrotic collections are primarily drained, and in case of no clinical improvement, there is a "step-up" towards necrosectomy. This step-up approach reduces the rates of new-onset multiple organ failure, morbidity, serious adverse events, and lower costs $[50,51]$ as compared to primary open necrosectomy, which has since largely been abandoned.

In the step-up approach, nearly half of the patients can be treated with drainages alone, the other half require additional different procedures for the final treatment, including percutaneous, endoscopic, open, or minimally invasive surgery $[17,50,52,53]$. In a systematic review including 10 retrospective series and one RCT with 384 patients who underwent percutaneous drainage because of acute necrotizing pancreatitis, percutaneous drainage was sufficient as definitive treatment in $56 \%$ of patients [54]. Another analysis showed that percutaneous drainage along with antibiotics was successful treatment in $50 \%$ of patients [55]. There are no comparative trials yet regarding catheter diameter, but large-bore catheters seem to less frequently obstruct by the necrotic debris. Upgrading drains to a larger diameter could be beneficial for the outcomes $[35,50,54,56]$. If the patient does not recover with drainage alone, necrosectomy is required. The traditional open necrosectomy has been largely replaced by minimally invasive techniques $[6,50,51]$. Of these, the most commonly used techniques include sinus tract endoscopy and video-assisted retroperitoneal debridement (VARD) [57, 58]. These techniques showed reduced morbidity and mortality, especially in high-risk groups of patients [59].

In the last decades, endoscopic transmural (i.e., transgastric) management of acute necrotizing pancreatitis is being increasingly performed. Various endoscopic techniques are used for the treatment of WON, all of these include transmural access to the cavity with or without endoscopic ultrasound (EUS). EUS-guided drainage and/ or necrosectomy has had advantage over conventional 
transmural endoscopic approach due to higher technical success $[40,42,60]$. Compared to surgical necrosectomy, an endoscopic approach significantly reduces proinflammatory response and improves clinical outcome in ANP patients [52]. However, when used as a single modality approach, it requires more sessions of necrosectomy for definitive treatment than in combination with other interventional procedures [53,61-63]. A large meta-analysis found that endoscopic necrosectomy has success rate of $81 \%$ as a single treatment modality with a complication rate of $36 \%$ [64]. In the largest randomized controlled trial, comparing endoscopic step-up approach with surgical step-up approach [53], both procedures have similar mortality rates and major complications. The surgical step-up approach, however, had a higher incidence of pancreatocutaneous fistula $[51,53]$.

\section{Conclusion}

The management of pancreatic fluid collections needs to be tailored for each patient. Multidisciplinary approach is crucial for adequate and timely treatment. Asymptomatic collections do not need drainage irrespective of their size. Infected collections may require intervention. Delaying intervention at least for 3-4 weeks after AP onset allows better decision in the selection of interventional approach. A minimally invasive step-up approach is superior to primary open surgery in terms of morbidity for all peripancreatic fluid collections and should be the treatment of choice. Decision on surgical/percutaneous or endoscopic treatment should be made on anatomy, location of the collection, and local expertise of endoscopists, radiologists, and surgeons.

\section{References}

1 Pancreatitis diagnosis and management. NICE guideline. March 2018. Available from: www.nice.org.uk

2 Banks PA, Bollen TL, Dervenis C, Gooszen HG, Johnson CD, Sarr MG, et al.; Acute Pancreatitis Classification Working Group. Classification of acute pancreatitis-2012: revision of the Atlanta classification and definitions by international consensus. Gut. 2013 Jan;62(1):102-11.

3 Rana SS, Sharma V, Sharma RK, Chhabra P, Gupta R, Bhasin DK. Clinical significance of presence and extent of extrapancreatic necrosis in acute pancreatitis. J Gastroenterol Hepatol. 2015 Apr;30(4):794-8.

4 Banks PA, Freeman ML; Practice Parameters Committee of the American College of Gastroenterology. Practice guidelines in acute pancreatitis. Am J Gastroenterol. 2006 Oct; 101(10):2379-400.

5 Traverso LW, Kozarek RA. Pancreatic necrosectomy: definitions and technique. J Gastrointest Surg. 2005 Mar;9(3):436-9.

6 Raraty MG, Halloran CM, Dodd S, Ghaneh P, Connor S, Evans J, et al. Minimal access retroperitoneal pancreatic necrosectomy: improvement in morbidity and mortality with a less invasive approach. Ann Surg. 2010 May; 251(5):787-93

7 Tan V, Charachon A, Lescot T, Chafaï N, Le Baleur Y, Delchier JC, et al. Endoscopic transgastric versus surgical necrosectomy in infected pancreatic necrosis. Clin Res Hepatol Gastroenterol. 2014 Dec;38(6):770-6.

8 Freeman ML, Werner J, van Santvoort HC, Baron TH, Besselink MG, Windsor JA, et al.; International Multidisciplinary Panel of Speakers and Moderators. Interventions for necrotizing pancreatitis: summary of a multidisciplinary consensus conference. Pancreas. 2012 Nov;41(8):1176-94.

9 Carnovale A, Rabitti PG, Manes G, Esposito P, Pacelli L, Uomo G. Mortality in acute pancreatitis: is it an early or a late event? JOP 2005 Sep;6(5):438-44.
10 Fu CY, Yeh CN, Hsu JT, Jan YY, Hwang TL. Timing of mortality in severe acute pancreatitis: experience from 643 patients. World J Gastroenterol. 2007 Apr;13(13):1966-9.

11 Thoeni RF. The revised Atlanta classification of acute pancreatitis: its importance for the radiologist and its effect on treatment. Radiology. 2012 Mar;262(3):751-64.

12 Pan G, Wan MH, Xie KL, et al. Classification and management of pancreatic pseudocysts. Medicine (Baltimore). 2015 Jun;94(24):e960.

13 Mayerle J, Talukdar R, Beyer G, et al. Interventional and endoscopic therapy of chronic pancreatitis. Pancreapedia. Exocrine Pancreas Knowledge Base; 2016. https://doi. org/10.3998/panc.2016.28.

14 Sarr MG, Banks PA, Bollen TL, Dervenis C, Gooszen HG, Johnson CD, et al. The new revised classification of acute pancreatitis 2012 . Surg Clin North Am. 2013 Jun;93(3):549-62.

15 van Grinsven J, van Brunschot S, van Baal MC, Besselink MG, Fockens P, van Goor H, et al.; Dutch Pancreatitis Study Group. Natural History of Gas Configurations and Encapsulation in Necrotic Collections During Necrotizing Pancreatitis. J Gastrointest Surg. 2018 Sep;22(9):1557-64.

16 Bradley EL 3rd. A clinically based classification system for acute pancreatitis. Summary of the International Symposium on Acute Pancreatitis, Atlanta, Ga, September 11 through 13, 1992. Arch Surg. 1993 May; 128(5):586-90.

17 Working Group IAP/APA Acute Pancreatitis Guidelines. IAP/APA evidence-based guidelines for the management of acute pancreatitis. Pancreatology. 2013;13(4 Suppl 2):e1-15.

18 Song TJ, Lee SS. Endoscopic drainage of pseudocysts. Clin Endosc. 2014 May;47(3):222-6.

19 Mier J, León EL, Castillo A, Robledo F, Blanco R. Early versus late necrosectomy in severe necrotizing pancreatitis. Am J Surg. 1997 Feb; 173(2):71-5
20 Besselink MG, Verwer TJ, Schoenmaeckers EJ, Buskens E, Ridwan BU, Visser MR, et al. Timing of surgical intervention in necrotizing pancreatitis. Arch Surg. 2007 Dec;142(12): 1194-201.

21 Lenhart DK, Balthazar EJ. MDCT of acute mild (nonnecrotizing) pancreatitis: abdominal complications and fate of fluid collections. AJR Am J Roentgenol. 2008 Mar;190(3):6439.

22 Andrén-Sandberg A, Dervenis C. Pancreatic pseudocysts in the 21 st century. Part II: natural history. JOP. 2004 Mar;5(2):64-70.

23 Andrén-Sandberg A, Ansorge C, Eiriksson K, Glomsaker T, Maleckas A. Treatment of pancreatic pseudocysts. Scand J Surg. 2005;94(2): 165-75.

24 Agalianos C, Passas I, Sideris I, Davides D, Dervenis C. Review of management options for pancreatic pseudocysts. Transl Gastroenterol Hepatol. 2018 Mar;3:18.

25 Parks RW, Tzovaras G, Diamond T, Rowlands BJ. Management of pancreatic pseudocysts. Ann R Coll Surg Engl. 2000 Nov;82(6): 383-7.

26 Muthusamy VR, Chandrasekhara V, Acosta $\mathrm{RD}$, Bruining $\mathrm{DH}$, Chathadi KV, Eloubeidi MA, et al.; ASGE Standards of Practice Committee. The role of endoscopy in the diagnosis and treatment of inflammatory pancreatic fluid collections. Gastrointest Endosc. 2016 Mar;83(3):481-8.

27 Dhaka N, Samanta J, Kochhar S, Kalra N, Appasani S, Manrai M, et al. Pancreatic fluid collections: what is the ideal imaging technique? World J Gastroenterol. 2015 Dec;21(48): 13403-10.

28 Holt BA, Varadarajulu S. The endoscopic management of pancreatic pseudocysts (with videos). Gastrointest Endosc. 2015 Apr;81(4): 804-12.

29 Zerem E, Hauser G, Loga-Zec S, Kunosić S, Jovanović P, Crnkić D. Minimally invasive treatment of pancreatic pseudocysts. World J Gastroenterol. 2015 Jun;21(22):6850-60. 
30 Wroński M, Cebulski W, Pawłowski W, Krasnodębski IW, Słodkowski M. Walled-off necrosis: safety of watchful waiting. Dig Dis Sci. 2015 Apr;60(4):1081-6.

31 Bakker OJ, van Santvoort H, Besselink MG, Boermeester MA, van Eijck C, Dejong K, et al.; Dutch Pancreatitis Study Group. Extrapancreatic necrosis without pancreatic parenchymal necrosis: a separate entity in necrotising pancreatitis? Gut. 2013 Oct;62(10):147580.

32 Rana SS, Bhasin DK, Sharma RK, Kathiresan J, Gupta R. Do the morphological features of walled off pancreatic necrosis on endoscopic ultrasound determine the outcome of endoscopic transmural drainage? Endosc Ultrasound. 2014 Apr;3(2):118-22.

33 Papachristou GI, Takahashi N, Chahal P, Sarr MG, Baron TH. Peroral endoscopic drainage/ debridement of walled-off pancreatic necrosis. Ann Surg. 2007 Jun;245(6):943-51.

34 Garg PK, Sharma M, Madan K, Sahni P, Banerjee D, Goyal R. Primary conservative treatment results in mortality comparable to surgery in patients with infected pancreatic necrosis. Clin Gastroenterol Hepatol. 2010 Dec; 8(12):1089-1094.e2.

35 Mouli VP, Sreenivas V, Garg PK. Efficacy of conservative treatment, without necrosectomy, for infected pancreatic necrosis: a systematic review and meta-analysis. Gastroenterology. 2013 Feb;144(2):333-340.e2.

36 Fernández-del Castillo C, Rattner DW, Makary MA, Mostafavi A, McGrath D, Warshaw AL. Débridement and closed packing for the treatment of necrotizing pancreatitis. Ann Surg. 1998 Nov;228(5):676-84.

37 Varadarajulu S, Bang JY, Sutton BS, Trevino JM, Christein JD, Wilcox CM. Equal efficacy of endoscopic and surgical cystogastrostomy for pancreatic pseudocyst drainage in a randomized trial. Gastroenterology. 2013 Sep; 145(3):583-90.e1.

38 Redwan AA, Hamad MA, Omar MA. Pancreatic Pseudocyst Dilemma: Cumulative Multicenter Experience in Management Using Endoscopy, Laparoscopy, and Open Surgery. J Laparoendosc Adv Surg Tech A. 2017 Oct; 27(10):1022-30.

39 Melman L, Azar R, Beddow K, Brunt LM, Halpin VJ, Eagon JC, et al. Primary and overall success rates for clinical outcomes after laparoscopic, endoscopic, and open pancreatic cystgastrostomy for pancreatic pseudocysts. Surg Endosc. 2009 Feb;23(2):267-71.

40 Park DH, Lee SS, Moon SH, Choi SY, Jung SW, Seo DW, et al. Endoscopic ultrasoundguided versus conventional transmural drainage for pancreatic pseudocysts: a prospective randomized trial. Endoscopy. 2009 Oct; 41(10):842-8

41 Varadarajulu S, Lopes TL, Wilcox CM, Drelichman ER, Kilgore ML, Christein JD. EUS versus surgical cyst-gastrostomy for management of pancreatic pseudocysts. Gastrointest Endosc. 2008 Oct;68(4):649-55.
42 Varadarajulu S, Christein JD, Tamhane A, Drelichman ER, Wilcox CM. Prospective randomized trial comparing EUS and EGD for transmural drainage of pancreatic pseudocysts (with videos). Gastrointest Endosc. 2008 Dec;68(6):1102-11.

43 Kahaleh M, Shami VM, Conaway MR, Tokar J, Rockoff T, De La Rue SA, et al. Endoscopic ultrasound drainage of pancreatic pseudocyst: a prospective comparison with conventional endoscopic drainage. Endoscopy. 2006 Apr;38(4):355-9.

44 Morton JM, Brown A, Galanko JA, Norton JA, Grimm IS, Behrns KE. A national comparison of surgical versus percutaneous drainage of pancreatic pseudocysts: 19972001. J Gastrointest Surg. 2005 Jan;9(1):1520.

45 Heider R, Meyer AA, Galanko JA, Behrns KE. Percutaneous drainage of pancreatic pseudocysts is associated with a higher failure rate than surgical treatment in unselected patients. Ann Surg. 1999 Jun;229(6):781-7.

46 Adams DB, Anderson MC. Percutaneous catheter drainage compared with internal drainage in the management of pancreatic pseudocyst. Ann Surg. 1992 Jun;215(6):5716.

47 Lang EK, Paolini RM, Pottmeyer A. The efficacy of palliative and definitive percutaneous versus surgical drainage of pancreatic abscesses and pseudocysts: a prospective study of 85 patients. South Med J. 1991 Jan;84(1): $55-64$.

48 Trevino JM, Tamhane A, Varadarajulu S. Successful stenting in ductal disruption favorably impacts treatment outcomes in patients undergoing transmural drainage of peripancreatic fluid collections. J Gastroenterol Hepatol. 2010 Mar;25(3):526-31.

49 Yang D, Amin S, Gonzalez S, Mullady D, Hasak S, Gaddam S, et al. Transpapillary drainage has no added benefit on treatment outcomes in patients undergoing EUS-guided transmural drainage of pancreatic pseudocysts: a large multicenter study. Gastrointest Endosc. 2016 Apr;83(4):720-9.

50 van Santvoort HC, Besselink MG, Bakker OJ, Hofker HS, Boermeester MA, Dejong $\mathrm{CH}$, et al.; Dutch Pancreatitis Study Group. A stepup approach or open necrosectomy for necrotizing pancreatitis. N Engl J Med. 2010 Apr; 362(16):1491-502.

51 Gurusamy KS, Belgaumkar AP, Haswell A, Pereira SP, Davidson BR. Interventions for necrotising pancreatitis. Cochrane Database Syst Rev. 2016 Apr;4:CD011383.

52 Bakker OJ, van Santvoort HC, van Brunschot S, Geskus RB, Besselink MG, Bollen TL, et al.; Dutch Pancreatitis Study Group. Endoscopic transgastric vs surgical necrosectomy for infected necrotizing pancreatitis: a randomized trial. JAMA. 2012 Mar;307(10):1053-61.

53 van Brunschot S, van Grinsven J, van Santvoort HC, Bakker OJ, Besselink MG, Boermeester MA, et al.; Dutch Pancreatitis Study Group. Endoscopic or surgical step-up approach for infected necrotising pancreatitis: a multicentre randomised trial. Lancet. 2018 Jan;391(10115):51-8.
54 van Baal MC, van Santvoort HC, Bollen TL, Bakker OJ, Besselink MG, Gooszen HG; Dutch Pancreatitis Study Group. Systematic review of percutaneous catheter drainage as primary treatment for necrotizing pancreatitis. Br J Surg. 2011 Jan;98(1):18-27.

55 Shenvi S, Gupta R, Kang M, Khullar M, Rana SS, Singh R, et al. Timing of surgical intervention in patients of infected necrotizing pancreatitis not responding to percutaneous catheter drainage. Pancreatology. 2016 SepOct;16(5):778-87.

56 van Grinsven J, Timmerman P, van Lienden KP, Haveman JW, Boerma D, van Eijck CH, et al.; Dutch Pancreatitis Study Group. Proactive Versus Standard Percutaneous Catheter Drainage for Infected Necrotizing Pancreatitis. Pancreas. 2017 Apr;46(4):518-23.

57 Carter CR, McKay CJ, Imrie CW. Percutaneous necrosectomy and sinus tract endoscopy in the management of infected pancreatic necrosis: an initial experience. Ann Surg. 2000 Aug;232(2):175-80.

58 Horvath KD, Kao LS, Wherry KL, Pellegrini CA, Sinanan MN. A technique for laparoscopic-assisted percutaneous drainage of infected pancreatic necrosis and pancreatic abscess. Surg Endosc. 2001 Oct;15(10):1221-5.

59 van Brunschot S, Hollemans RA, Bakker OJ, Besselink MG, Baron TH, Beger HG, et al. Minimally invasive and endoscopic versus open necrosectomy for necrotising pancreatitis: a pooled analysis of individual data for 1980 patients. Gut. 2018 Apr;67(4):697-706.

60 Arvanitakis M, Dumonceau JM, Albert J, Badaoui A, Bali MA, Barthet M, et al. Endoscopic management of acute necrotizing pancreatitis: european Society of Gastrointestinal Endoscopy (ESGE) evidence-based multidisciplinary guidelines. Endoscopy. 2018 May; 50(5):524-46.

61 Varadarajulu S, Phadnis MA, Christein JD, Wilcox CM. Multiple transluminal gateway technique for EUS-guided drainage of symptomatic walled-off pancreatic necrosis. Gastrointest Endosc. 2011 Jul;74(1):74-80.

62 Ang TL, Kwek AB, Tan SS, Ibrahim S, Fock KM, Teo EK. Direct endoscopic necrosectomy: a minimally invasive endoscopic technique for the treatment of infected walled-off pancreatic necrosis and infected pseudocysts with solid debris. Singapore Med J. 2013 Apr; 54(4):206-11.

63 Gluck M, Ross A, Irani S, Lin O, Gan SI, Fotoohi M, et al. Dual modality drainage for symptomatic walled-off pancreatic necrosis reduces length of hospitalization, radiological procedures, and number of endoscopies compared to standard percutaneous drainage. J Gastrointest Surg. 2012 Feb;16(2):24856.

64 van Brunschot S, Fockens P, Bakker OJ, Besselink MG, Voermans RP, Poley JW, et al. Endoscopic transluminal necrosectomy in necrotising pancreatitis: a systematic review. Surg Endosc. 2014 May;28(5):1425-38. 
